\title{
Effect of dimerized melittin on gastric cancer cells and antibacterial activity
}

Elaheh Jamasbi ${ }^{1}$, Sasidharan S. Lucky ${ }^{2}$, Wenyi $\mathrm{Li}^{1}$, M. Akhter Hossain ${ }^{3}$, Ponnampalam Gopalakrishnakone $^{2}$ and Frances Separovic ${ }^{1}$

${ }^{1}$ School of Chemistry, Bio21 Institute, University of Melbourne, VIC 3010, Australia

${ }^{2}$ Department of Anatomy, Yong Loo Lin School of Medicine, 4 Medical Drive, National University of Singapore, Singapore 117594

${ }^{3}$ The Florey Institute of Neuroscience and Mental Health, University of Melbourne, VIC 3010, Australia

Corresponding author: Frances Separovic http://orcid.org/0000-0002-6484-2763

Email: fs@unimelb.edu.au Phone: +61 390357539

Key words: lytic peptide, cytotoxicity, confocal microscopy, cell membranes

Acknowledgements: FS acknowledges the Australian Research Council for award of grant DP140102127. 


\begin{abstract}
Melittin is the peptide toxin found in bee venom and is effective against cancer cells. In order to enhance its activity, a branched dimeric form of melittin was designed. The monomeric form of the peptide was more cytotoxic against gastric cancer cells at low concentrations (1-5 $\mu \mathrm{M})$ than the dimer form, while the cytotoxic effect was comparable at higher concentrations $(10 \mu \mathrm{M})$. Confocal microscopy showed that both the monomer and dimer forms of melittin with fluorescent label at the C-terminus penetrated the cytoplasm and localized at the cell nucleus and disrupted the cell membrane. The results indicated that both peptides localized in the nucleus and no significant difference in penetration was observed between monomer and dimer of melittin. Although the $\mathrm{C}$ - and N-termini are important for melittin activity, using $\mathrm{C}$ terminus for dimerization of the peptide resulted in similar activity for the monomer and dimer against bacteria and gastric cancer cells.
\end{abstract}

\title{
Introduction
}

Cancer is a serious health issue and novel anticancer drugs are needed urgently due to harmful side effects of chemotherapy (Huang et al. 2015). Increasingly, natural products such as biotoxins (Liu et al. 2016) are being investigated for the treatment of cancer. Melittin, a cationic peptide of 26 amino acids from bee toxin (Jamasbi et al. 2014), is a promising candidate for cancer therapy due to anti-cancer effects in mouse models and preclinical cell cultures (Rady et al. 2017). Anti-cancer properties of melittin against different cell lines such as HeLa (Jamasbi et al. 2015), ovarian cancer (Jo et al. 2012) and gastric cancer (Kong et al. 2016) have been reported. Amongst these, gastric cancer is recognized as the fourth most common cancer and the second cancer leading to death worldwide (Giordano and Cito 2012; Siegel et al. 2013). Melittin potentially prevent metastasis of tumour cells by minimizing cell motility (Jamasbi et al. 2016). Conjugation of melittin with hormone receptors and gene therapy carrying melittin are a novel candidate for the treatment of prostate and breast cancer (Orsolic 2012). However, the mechanisms of anti-metastasis remain elusive (Liu et al. 2008). Application of melittin as an anti-cancer drug is a challenge due to its non-specific cytotoxicity and haemolytic activity (Liu et al. 2016).

The conformation of melittin depends on its environment but how melittin self-assembles under different conditions is unclear. The peptide has a range of different conformations, 
including random coil, $\alpha$-helix and a self-assembled tetramer (Qiu et al. 2005; Miura 2012). Melittin is unstructured at neutral $\mathrm{pH}$ and low ionic and peptide concentrations (Gribenko et al. 2002). The $\alpha$-helical tetramer conformation can be induced at high $\mathrm{pH}$, salt and peptide concentrations (Othon et al. 2009). Melittin is often active in a tetrameric form (Terra et al. 2007) when inserted into lipid bilayers (Sun et al. 2015) and exists as a dimer of dimers (Iwadate et al. 1998). The tetrameric form consists of two helical regions (residues 2-11 and 13-23) separated by a proline residue and unstructured C-terminus region (Iwadate et al. 1998).

We previously have shown that blocking the $\mathrm{N}$-terminus of melittin resulted in a decrease of cytotoxic activity against HeLa cells (Jamasbi et al. 2015). To gain better understanding of melittin action and determine the role of dimerization and C-terminus in melittin activity, we synthesized a dimeric form of melittin conjugated at the C-terminus using 3,3'diaminobenzidine (Dab). The peptides were also tagged with fluorescent label AlexaFluor 430 and activity against gastric cancer cells was studied. To determine the effect of the blocked C-terminus on the peptide activity of melittin, we used four bacterial lines and three gastric cancer cell lines (NUGC-3, MKN-7, MKN-74), and studied the cellular binding and localization as well as cytotoxicity. For comparison, monomeric and dimeric forms of melittin labelled utilizing the C-terminus were used for the study.

\section{Experimental}

\section{Solid Phase Peptide Synthesis (SPPS)}

Fmoc solid-phase methods were used to synthesize the peptides(Fields and Noble 1990). Peptides were assembled on a CEM Liberty (DKSH Ltd, Melbourne, Australia) microwave peptide synthesizer. Using 3,3-diaminobenzidine (Dab) branching ( $\mathrm{Li}$ et al. 2017; Li et al. 2015), we synthesized a dimeric form of melittin. An additional cysteine at the C-terminus was used to label the peptides (Fig. 1). The peptides were cleaved from the polystyrene resin using trifluoroacetic (TFA) in the presence of anisole, triisopropylsilane and water (ratio 95:3:1:1) for $2 \mathrm{~h}$ at room temperature. Reversed-phase high performance liquid chromatography (RP-HPLC) in water and acetonitrile with $0.1 \%$ TFA was used to purify peptides. 


\section{Peptide labelling}

Monomer and dimer of melittin were labelled using thiol-maleimide conjugation chemistry strategy. The peptides with additional cysteine were dissolved in phosphate buffered saline (PBS) $\mathrm{pH}$ 7.4. The maleimide derivative of AlexaFluor 430 (Invitrogen, Sydney, Australia) was dissolved in Milli-Q water at $1 \mathrm{mg} / \mathrm{ml}$. AlexaFluor 430 was then reacted with cysteinederivatized peptides. The reaction was carried on for $1 \mathrm{~h}$ at room temperature. The product was purified by RP-HPLC in water and acetonitrile with $0.1 \%$ TFA and characterized by MALDI-TOF mass spectrometry.

\section{Antibacterial activity and minimum inhibitory concentration (MIC)}

MICs of melittin peptides against four Gram-negative bacteria namely E. coli, $K$. pnuemoniae, $P$. aeruginosa and A. baumannii, were determined in Luria broth (LB) according to the Lambert and Pearson analysis method. All bacterial strains were cultured on blood agar plates (Oxoid blood agar base, no.2; ThermoScientific, Sydney, Australia) supplemented with $10 \%$ (v/v) lysed horse blood (Equicell, Sydney, Australia) at $37^{\circ} \mathrm{C}$. $2.5 \times 10^{5} / \mathrm{ml}$ viable bacterial cells $(100 \mu \mathrm{l}$ of stock suspension) were added to serial dilutions of $200 \mu \mathrm{M}$ peptide in sterile distilled water into LB (10 g of tryptone/L, $5 \mathrm{~g}$ of yeast extract/L, $10 \mathrm{~g}$ of $\mathrm{NaCl}, \mathrm{pH} 7.5$ ) in 96-well microtiter plates (Interpath Service, Melbourne, Australia), ranging from 0.16-84.7 $\mu \mathrm{M}$ monomer and 0.04-21.2 $\mu \mathrm{M}$ dimer, and incubated at $37^{\circ} \mathrm{C}$. The bacterial growth to determine MICs was monitored at 20 min intervals over a $16 \mathrm{~h}$ period at an optical density at $620 \mathrm{~nm}\left(\mathrm{OD}_{620}\right)$ using an iEMS microplate reader (Pathtech Pty Ltd, Melbourne, Australia). The optical density of the culture was then adjusted with sterile saline to be the same as that of a $0.5 \mathrm{McFarland}$ standard. The cultures were then diluted 1 in 100 in cation-adjusted Mueller-Hinton broth (CAMHB). Following inoculation, each well contained approximately $5 \times 10^{5}$ colony-forming units $/ \mathrm{ml}$. To prevent drying, each tray was sealed with plastic tape before incubation overnight at $37^{\circ} \mathrm{C}$. Microtiter wells were read visually for determination of the MIC. Two growths (no added peptide), and two negative (uninoculated) control wells were included for each test strain. The comparative growth was compared with maximal growth at each concentration of peptides. The MIC was determined as the lowest concentration of peptides that completely inhibited the growth of the bacteria. 


\section{Binding and localization of melittin in gastric cancer cells}

Peptide localization into cells is a subject of debate in medicinal chemistry. However, entrance into cells has been reported for some cationic peptides (Ragin et al. 2002). Fluorescent melittin peptides were prepared to study colocalization of melittin peptides with cell membranes. Confocal microscopy was used to image cells after treatment with melittin peptides. 25,000 gastric cancer cells per well were seeded in 8 well chambered slides (Nunc $^{\text {TM }}$ Lab-Tek ${ }^{\text {TM }}$ II Chamber Slide ${ }^{\text {TM }}$ System) and incubated overnight. Actin cytoskeleton was labelled with $5 \mu \mathrm{g} / \mathrm{mL}$ TRITC-conjugated Phalloidin (Sigma-Aldrich) (excitation/emission maxima $\sim 540 / 565 \mathrm{~nm}$ ) and incubated for $10 \mathrm{~min}$. The nucleus was stained with Hoechst 33342 (Invitrogen H3570, 10 mg/ml) (Ex/Em: 350/461) diluted 1:2000 in Hank's balanced salt solution (HBSS). The cells were then treated with $250 \mu \mathrm{L}$ of $1 \mu \mathrm{M}$ melittin peptides in HBSS, while performing the live cell imaging using an inverted Olympus FluoView FV1000 confocal laser scanning microscope.

\section{Cytotoxicity assay}

Cell viability was determined using MTS assay (Riss 2004). The MTS compound is bioreduced by cells into a colored formazan product that is soluble in tissue culture medium. The quantity of formazan product as measured by the amount of $490 \mathrm{~nm}$ absorbance is directly proportional to the number of living cells in culture. Three gastric cancer cell-lines were chosen for testing the cell viability when treated with monomer or dimer of melittin. Cells were seeded at a density of $10^{4}$ cells per well and grown in complete RPMI medium (with $10 \%$ serum) then trypsinized and harvested and maintained in a humidified incubator at $37^{\circ} \mathrm{C}, 5 \% \mathrm{CO}_{2}$ for $24 \mathrm{~h}$. Cells were then treated with $0.05,1,5,10$ and $20 \mu \mathrm{M}$ melittin peptides and incubated for $24 \mathrm{~h}$ after which $100 \mu \mathrm{l}$ of the conditioned media was transferred to a 96-well flat-bottom plate, and the cell toxicity was measured using the Celltiter 96 Aqueous One Solution cell proliferation assay (Promega, USA), according to manufacturer's instruction. Absorbance was measured at $490 \mathrm{~nm}$ in the Tecan infinite Pro200 spectrophotometer. Maximum fluorescence intensity was determined by adding $2 \mu 1$ of $9 \%$ Triton X-100 to cells as a positive control; cells incubated with PBS were the vehicle control.

\section{Reactive oxygen species (ROS)}

200,000 NUGC-3 gastric cancer cells were seeded in a glass bottom dish and allowed to attach overnight. Following a gentle wash with HBSS, cells were treated with $250 \mu \mathrm{l}$ of 10 
$\mu \mathrm{M}$ melittin, melittin dimer or $100 \mathrm{uM}$ tert-butylhydroperoxide (positive control) and incubated at $37^{\circ} \mathrm{C}$ for 15 mins. Thereafter, cells were treated with $25 \mu \mathrm{M}$ carboxy-2',7'dichlorodihydrofluorescein diacetate (carboxy-H2DCFDA) for 30 mins at $37^{\circ} \mathrm{C}$ protected from light. The cells were then counterstained with Hoechst 33342 and cell mask deep red for 5 mins before imaging using an inverted Olympus Fluoview FV1000 confocal laser scanning microscope.

\section{Haemolysis}

Female Balb/c nude mice, 12-15 weeks of age, weighing an average of $21 \mathrm{~g}$ were obtained from InVivos, Singapore. All procedures were approved by the Institutional Animal Care and Use Committee, NUS, Singapore (Protocol approval number: R15-0242) and performed in accordance with international standards. The mice were anaesthetized by intraperitoneal injection of $200 \mu \mathrm{l}$ of an anaesthetic cocktail (ketamine:diazepam:saline, 6: 9: 10) before drawing blood via cardiac puncture. Red blood cells (RBCs) were separated from fresh mice blood $(\sim 800 \mu \mathrm{l})$ by centrifuging at $1500 \mathrm{rpm}$ for $15 \mathrm{~min}$ at $4^{\circ} \mathrm{C}$. Isolated RBCs were further washed three times with sterile PBS by centrifugation until the supernatant was clear, and resuspended in $2 \mathrm{ml}$ sterile PBS. $100 \mu \mathrm{l}$ of the RBC suspension was then treated with $100 \mu \mathrm{l}$ of either melittin or melittin dimer at different concentrations (range $1-10 \mu \mathrm{M}$ ). Following 2 $\mathrm{h}$ incubation at $37^{\circ} \mathrm{C}$ under constant shaking, the suspensions were centrifuged at $1500 \mathrm{rpm}$ for $15 \mathrm{~min}$ at room temperature. Subsequently, $100 \mu 1$ of supernatant from each centrifuge tube was used to analyse hemoglobin release by microplate reader (Tecan Safire2, Männedorf, Switzerland) at wavelength of $576 \mathrm{~nm}$. Control experiments were performed under the same experimental conditions, where $100 \mu 1$ of the RBC suspension was added to $100 \mu \mathrm{l}$ of PBS as a negative control and to $100 \mu \mathrm{l}$ of $0.5 \%$ Triton X-100 as a positive control. The percentage haemolysis was calculated using the following equation: Haemolysis $(\%)=\left(\mathrm{OD}_{576}\right.$ sample $-\mathrm{OD}_{576}$ negative control $) /\left(\mathrm{OD}_{576}\right.$ positive control $\mathrm{OD}_{576}$ negative control) $\times 100 \%$

\section{Statistical analysis}

All data were obtained from at least three biological replicates and expressed as mean \pm standard deviation as indicated by the error bars. Statistical analysis was carried out using univariate analysis of variance (ANOVA). 


\section{Results and Discussions}

\section{Synthesis of melittin peptides}

Melittin is a lytic peptide that forms $\alpha$-helices which aggregate on the membrane and form pores (Raghuraman and Chattopadhyay 2007). Dimerization of melittin is proposed to be an important step in the mechanism of pore formation. The melittin cysteine monomer and its dimer were synthesized using solid phase peptide synthesis. To determine the role of the Cterminus in the action mechanism of melittin, a melittin dimer and dimer with additional cysteine in C-terminus were synthesized using Dab branching synthesis. Additional cysteine at the C-terminus was used for labelling the monomer and dimer of melittin with AlexaFluor 430 as described previously (Jamasbi et al. 2015). The RP-HPLC profile and MALDI-TOF mass spectra of the peptides are shown in Figure 2.

\section{Antibacterial activity}

Binding of melittin to cell membranes is required for pore formation(van den Bogaart et al. 2008) which leads to cell lysis (Jamasbi et al. 2016). Following the dimerization of the melittin peptide, the antimicrobial activity of monomer and dimer were compared against the Gram-negative bacterium in LB broth, to find out if blocking the C-terminus would affect the antibacterial activity of the dimer. In addition to that, it is also important to examine if the dimeric form of melittin enhanced the lytic activity of the peptide in comparison to the monomer. In the case of K. pneumoniae ATCC 13883, the dimer was more effective than the monomer (MIC 3.5 vs. $15 \mu \mathrm{M}$ ) (Table 1). The MIC values for the dimer were lower than that induced by the monomer for all four bacterial strains tested but approximately within a factor of two (Table 1). It is to be noted that the antibacterial activity of melittin dimer was not lost despite utilization of the C-terminus for the synthesis of dimer. Presumably, the antibacterial activity of melittin might be fulfilled by its $\mathrm{N}$ - rather than $\mathrm{C}$-terminus.

\section{Peptide localization in gastric cancer cells}

To better understand the importance of its C-terminus, we further analysed the anticancer activity of melittin peptides using gastric cancer as a model. Melittin has the ability to cross the cytoplasmic barrier and enter the cell nucleus (Zhang et al. 2016). Melittin entry into cells have been reported to involve endocytic receptors neuropilin-1, low-density lipoprotein- 
related protein receptor 1 (LRP1) and transferrin receptors (Kohno et al. 2014). The entry and localization of the synthesized melittin peptides in gastric cancer cells were studied by confocal microscopy. Our results indicated that both monomer and dimer forms of melittin localized in the cytoplasm and even at the membrane of the nucleus as early as $30 \mathrm{~min}$ (Fig. 3A \& 3B). Furthermore, there was no difference in the amount of monomer and dimer of melittin peptides that localized in the cells after 30 as well as 60 min treatment (Fig. 4 and Fig. 5), showing that the dimer was as effective as the monomer in penetrating and localizing within the cancer cells. The monomers in solution may remain as monomers and penetrate the cell membrane bilayer with higher efficiency due to their smaller size. Once in the cell membrane, melittin may form dimers and pores that lead to cell death (Jamasbi et al. 2016). However, at higher concentrations $(10 \mu \mathrm{M})$ the monomers may form dimers or tetramers more readily and thus the binding and cell killing efficiency of monomer is similar to dimer at higher concentrations. Hence, the concentration of melittin and form of peptide whether monomer or dimer in solution is an important determinant of its cytotoxic efficiency. To further determine the effect of addition of the dimer to the cancer cells, we performed live time lapse confocal imaging. Within 1 min following the addition of the dimer, membrane blebbing was observed, and eventually resulted in shrinkage of the nucleus, probably due to disruption of the nuclear membrane (Fig. 6 and Video file).

\section{Cytotoxicity assay}

The cytotoxicity of melittin peptides was evaluated using three different gastric cancer cell lines, based on their metastatic activity (Fig. 7). The dimer melittin exhibited a dose dependent cytotoxicity but the cytotoxicity of the melittin monomer was comparatively higher than that of the dimer, although at the higher concentrations was comparable. The results show that both monomer and dimer melittin are toxic against MKN-74 and less cytotoxic against MKN-7, which may indicate that metastatic potency of cell lines may be important for melittin efficacy. Also, the presence of the fluorescent tag seemed to reduce the cell killing efficiency of both melittin monomer and dimer, which is consistent with our previous reported findings (Jamasbi et al. 2015).

\section{Reactive oxygen species (ROS)}

Oxidative stress is characterized by over production of ROS which leads to defects in mitochondria membrane permeability. ROS induces mitochondrial DNA mutation and damage to the respiratory chain (Guo et al. 2013). To further evaluate the mechanistic 
pathway preceding the activation of apoptotic cell death, ROS generation ability of both melittin monomer and dimer were studied by incubating NUGC-3 gastric cancer cells with fluorogenic marker of ROS, namely (carboxy-H2DCFDA). Carboxy- $\mathrm{H}_{2}$ DCFDA is not fluorescent but in the presence of ROS, it is oxidized and becomes fluorescent (Wu and Yotnda 2011). Cells were found to have bright green fluorescence indicating the production of ROS (Figure 8). The results also indicate that melittin dimer generates ROS more efficiently than monomer. Increased ROS production may trigger mitochondrial membrane lipid peroxidation, membrane fluidity reduction and membrane lipid degradation, which ultimately lead to formation of apoptotic bodies that trigger the apoptotic pathway of cell death (Barrera 2012).

\section{Haemolysis}

Haemolytic activity of native melittin has been widely reported (Jamasbi et al. 2014). Red blood cell lysis is the results of binding melittin to cell membrane and is observed when about $1 \%$ of melittin binding sites are occupied (Tosteson et al. 1985). 1, 5 and $10 \mu \mathrm{M}$ concentrations of melittin peptides were used to assay haemolytic activity and the results indicated that the melittin dimer was dose dependent for RBC lysis (Fig. 9). At $10 \mu \mathrm{M}$, both monomer and dimer were almost $100 \%$ lytic but at $1 \mu \mathrm{M}$ the dimer was more lytic; while at 5 $\mu \mathrm{M}$ the monomer was more effective against RBCs, possibly due to its smaller size as discussed above for the gastric cell penetration.

\section{Conclusion}

Melittin peptides are known to enter cells and co-localize at the nuclear membrane. A dimer of melittin conjugated at the C-terminus was synthesized and both it and the monomer were fluorescently labelled by adding a cysteine at the C-terminus. In earlier work (Jamasbi et al. 2015), a decrease in activity was observed when the N-terminus was modified but, in the present study where the C-terminus has been modified, activity is preserved. The MICs observed for the dimer indicated slightly higher activity against bacteria. The cytotoxicity assay indicated that the melittin dimer had dose dependent activity and that AlexaFluor 430 attached to the cysteine at the $\mathrm{C}$-terminus decreased the cytotoxicity of the peptides. Confocal microscopy showed that both monomer and dimer melittin entered the cytoplasm and located at the nucleus of the cells although more monomer penetrated into the cells. Membrane binding of both melittin peptides was observed and, although both produced ROS, which 
maybe a cause of cell death, the dimer produced more ROS. Although the dimer had about twice the activity as the monomer in bacterial cells, this was not the case with cancer and RBCs. Overall, both the melittin monomer and dimer aggregate through interaction with the membrane. However, when considering the dimer, there are several aspects of melittin that change, including: (i) the accessibility of the C-terminus, (ii) the double number of melittin chains for the same peptide concentration, and (iii) the increase in molecular size. These three differences may influence the interactions in a different manner when comparing observations for both molecules. For instance, the two-fold increase of antibacterial activity for the dimer could be as result that there are two melittin chains for the same molar concentration. Further work is needed using model membranes to determine the mechanism of action for the melittin dimer. Nevertheless, care needs to be taken when modifying melittin as the site of dimerization and the fluorophore affects the peptide activity.

The authors do not have potential conflicts of interest. This research did not involve Human Participants and/or Animals and does not require Informed Consent.

\section{References}

Barrera G (2012) Oxidative Stress and lipid peroxidation products in cancer progression and therapy. ISRN Oncology 2012:21.

Fields GB, Noble RL (1990) Solid phase peptide synthesis utilizing 9-fluorenylmethoxycarbonyl amino acids. International journal of peptide and protein research 35 (3):161-214.

Giordano A, Cito L (2012) Advances in gastric cancer prevention. World Journal of Clinical Oncology 3 (9):128-136.

Gribenko AV, Guzman-Casado M, Lopez MM, Makhatadze GI (2002) Conformational and thermodynamic properties of peptide binding to the human S100P protein. Protein Science 11 (6):1367-1375.

Guo C, Sun L, Chen X, Zhang D (2013) Oxidative stress, mitochondrial damage and neurodegenerative diseases. Neural Regeneration Research 8 (21):2003-2014.

Huang Y, Feng Q, Yan Q, Hao X, Chen Y (2015) Alpha-helical cationic anticancer peptides: a promising candidate for novel anticancer drugs. Mini Reviews in Medicinal Chemistry 15 (1):73-81.

Iwadate M, Asakura T, Williamson MP (1998) The structure of the melittin tetramer at different temperatures - an NOE-based calculation with chemical shift refinement. European Journal of Biochemistry 257 (2):479-487.

Jamasbi E, Batinovic S, Sharples RA, Sani MA, Robins-Browne RM, Wade JD, Separovic F, Hossain MA (2014) Melittin peptides exhibit different activity on different cells and model membranes. Amino Acids 46 (12):2759-2766.

Jamasbi E, Ciccotosto GD, Tailhades J, Robins-Browne RM, Ugalde CL, Sharples RA, Patil N, Wade JD, Hossain MA, Separovic F (2015) Site of fluorescent label modifies interaction of melittin with live cells and model membranes. Biochimica et Biophysica Acta 1848 (10 Pt A):2031-2039.

Jamasbi E, Mularski A, Separovic F (2016) Model membrane and cell studies of antimicrobial activity of melittin analogues. Current Topics in Medicinal Chemistry 16 (1):40-45. 
Jo M, Park MH, Kollipara PS, An BJ, Song HS, Han SB, Kim JH, Song MJ, Hong JT (2012) Anti-cancer effect of bee venom toxin and melittin in ovarian cancer cells through induction of death receptors and inhibition of JAK2/STAT3 pathway. Toxicology and Applied Pharmacology 258 (1):72-81.

Kohno M, Horibe T, Ohara K, Ito S, Kawakami K (2014) The membrane-lytic peptides K8L9 and melittin enter cancer cells via receptor endocytosis following subcytotoxic exposure. Chemistry \& Biology 21 (11):1522-1532.

Kong G-M, Tao W-H, Diao Y-L, Fang P-H, Wang J-J, Bo P, Qian F (2016) Melittin induces human gastric cancer cell apoptosis via activation of mitochondrial pathway. World Journal of Gastroenterology 22 (11):3186-3195.

Li W, O'Brien-Simpson NM, Tailhades J, Pantarat N, Dawson RM, Otvos L, Jr., Reynolds EC, Separovic F, Hossain MA, Wade JD (2015) Multimerization of a proline-rich antimicrobial peptide, CHEX-Arg20, alters its mechanism of interaction with the Escherichia coli membrane. Chemistry \& Biology 22 (9):1250-1258.

Li W, O'Brien-Simpson NM, Yao S, Tailhades J, Reynolds EC, Dawson RM, Otvos L, Jr., Hossain MA, Separovic F, Wade JD (2017) C-Terminal modification and multimerization increase the efficacy of a proline-rich antimicrobial peptide. Chemistry (Weinheim an der Bergstrasse, Germany) 23 (2):390-396.

Liu C-C, Hao D-jJ Zhang Q, An J, Zhao J-J, Chen B, Zhang L-I, Yang H (2016) Application of bee venom and its main constituent melittin for cancer treatment. Cancer Chemotherapy and Pharmacology 78 (6):1113-1130.

Liu S, Yu M, He Y, Xiao L, Wang F, Song C, Sun S, Ling C, Xu Z (2008) Melittin prevents liver cancer cell metastasis through inhibition of the Rac1-dependent pathway. Hepatology (Baltimore, Md) 47 (6):1964-1973.

Miura Y (2012) NMR studies on the monomer-tetramer transition of melittin in an aqueous solution at high and low temperatures. European Biophysics Journal 41 (7):629-636.

Orsolic N (2012) Bee venom in cancer therapy. Cancer Metastasis Reviews 31 (1-2):173-194.

Othon CM, Kwon O-H, Lin MM, Zewail AH (2009) Solvation in protein (un)folding of melittin tetramer-monomer transition. Proceedings of the National Academy of Sciences 106 (31):12593-12598.

Qiu W, Zhang L, Kao YT, Lu W, Li T, Kim J, Sollenberger GM, Wang L, Zhong D (2005) Ultrafast hydration dynamics in melittin folding and aggregation: helix formation and tetramer selfassembly. Journal of Physical Chemistry B 109 (35):16901-16910.

Rady I, Siddiqui IA, Rady M, Mukhtar H (2017) Melittin, a major peptide component of bee venom, and its conjugates in cancer therapy. Cancer Letters 402:16-31.

Raghuraman H, Chattopadhyay A (2007) Melittin: a membrane-active peptide with diverse functions. Bioscience Reports 27 (4-5):189-223.

Ragin AD, Morgan RA, Chmielewski J (2002) Cellular Import mediated by nuclear localization signal peptide sequences. Chemistry \& Biology 9 (8):943-948.

Riss TL, Moravec RL, Niles AL, Duellman S, Benink HA, Worzella TJ, Minor L (2013) Cell viability assays. In: Sittampalam GS, Coussens NP, Brimacombe K, et al., editors. Assay Guidance Manual [Internet]. Bethesda (MD): Eli Lilly \& Company and the National Center for Advancing Translational Sciences; 2004-. http://europepmc.org/books/NBK144065

Siegel R, Naishadham D, Jemal A (2013) Cancer statistics, 2013. CA: A Cancer Journal for Clinicians 63 (1):11-30.

Sun D, Sun M, Zhu W, Wang Z, Li Y, Ma J (2015) The Anti-cancer potency and mechanism of a novel tumor-activated fused toxin, DLM. Toxins 7 (2):423-438.

Terra RM, Guimaraes JA, Verli H (2007) Structural and functional behavior of biologically active monomeric melittin. Journal of Molecular Graphics \& Modelling 25 (6):767-772.

Tosteson MT, Holmes SJ, Razin M, Tosteson DC (1985) Melittin lysis of red cells. The Journal of Membrane Biology 87 (1):35-44. 
van den Bogaart G, Guzmán JV, Mika JT, Poolman B (2008) On the Mechanism of Pore Formation by Melittin. Journal of Biological Chemistry 283 (49):33854-33857.

Wu D, Yotnda P (2011) Production and detection of reactive oxygen species (ROS) in cancers. Journal of Visualized Experiments : JoVE (57):3357.

Zhang D, Wang J, Xu D (2016) Cell-penetrating peptides as noninvasive transmembrane vectors for the development of novel multifunctional drug-delivery systems. Journal of Controlled Release 229 (Supplement C):130-139. 
Table 1. Minimum inhibitory concentration $(\mu \mathrm{M}) *$ of melittin peptides.

\begin{tabular}{|c|c|c|c|c|}
\hline & $\begin{array}{c}\text { E. coli } \\
\text { ATCC 29222 }\end{array}$ & $\begin{array}{c}\text { K. pneumoniae } \\
\text { ATCC 13883 }\end{array}$ & $\begin{array}{c}\text { P. aeruginosa } \\
\text { ATCC 47085 }\end{array}$ & $\begin{array}{c}\text { A. baumannii } \\
\text { ATCC 19606 }\end{array}$ \\
\hline MLT & $13.2 \pm 1.6$ & $14.9 \pm 2.0$ & $12.1 \pm 0.5$ & $8.3 \pm 1.1$ \\
\hline dimer-MLT & $6.3 \pm 1.4$ & $3.5 \pm 0.01$ & $4.9 \pm 1.4$ & $4.1 \pm 0.1$ \\
\hline
\end{tabular}

* Mean of three separate determinations 


\section{Figure captions}

Figure 1. Structure of melittin: (A) monomer, (B) monomer AlexaFluor 430, (C) dimer, and (D) dimer AlexaFluor 430.

Figure 2. RP-HPLC and MALDI TOF MS traces of: (A) melittin, (B) melittin-AlexaFluor 430, (C) dimer-melittin, and (D) dimer-melittin-AlexaFluor 430.

Figure 3. Localization of (A) monomer, and (B) dimer melittin peptides in NUGC-3 gastric cancer cells using confocal microscopy. Red (TRITC) - actin filament, blue (Hoechst) nucleus, green melittin-AlexaFluor 430 after 30 and 60 mins with 3D reconstruction. Scale bar presents $20 \mu \mathrm{m}$.

Figure 4. Percentage of co-localization of melittin peptides within gastric cancer cells: monomer melittin-AlexaFluor 430 treatment for $30 \mathrm{~min}$ (crosshatched) and $60 \mathrm{~min}$ (white); and dimer melittin-AlexaFluor 430 treatment for $30 \mathrm{~min}$ (grey), and $60 \mathrm{~min}$ (black).

Figure 5. Binding of (A) monomer, and (B) dimer of melittin peptides to NUGC-3 gastric cancer cells. Scale bar presents $20 \mu \mathrm{m}, \mathrm{N}=3$.

Figure 6. Time lapse image showing the effect of melittin dimer on NUGC-3 cells.

Figure 7. The cell viability of gastric cancer cells, (A) NUGC-3, (B) MKN-7, and (C) MKN74 , following treatment with 1,5 and $10 \mu \mathrm{M}$ of monomer melittin (white), monomer melittinAlexaFluor 430 (light grey), dimer melittin (medium grey), and dimer melittin-AlexaFluor 430 (dark grey), was determined by using the MTT assay after $24 \mathrm{~h}$ incubation with each test compound. Results are mean +/- SEM, N=3.

Figure 8. Induction of ROS production following treatment with melittin. NUGC-3 cells were treated with $5 \mu \mathrm{g} / \mathrm{ml}$ melittin for $3 \mathrm{~h}$, followed by 30 mins incubation with $25 \mu \mathrm{M}$ carboxy-H2DCFDA. Green fluorescence represents cell with ROS production. $100 \mu \mathrm{M}$ TBHP (tert-butyl hydroperoxide) acts as the positive control. 
Figure 9. Haemolytic activity of 1, 5 and $10 \mu \mathrm{M}$ of monomer and dimer of melittin peptides. Triton X-100 (black), monomer of melittin (white), dimer of melittin (grey). Results are mean +/- SEM, N=3. 
Figure 1

GIGAVLKVLTTGLPALISWIKRKRQQ-NH 2

GIGAVLKVLTTGLPALISWIKRKRQQC-NH ${ }_{2}$

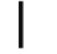

AlexaFluor430

(B)

GIGAVLKVLTTGLPALISWIKRKRQQ

GIGAVLKVLTTGLPALISWIKRKRQQ

Dab- $\mathrm{NH}_{2} \quad$ (C)

GIGAVLKVLTTGLPALISWIKRKRQQ

GIGAVLKVLTTGLPALISWIKRKRQQ $\left.\right|_{\text {AlexaFluor430 }} ^{\text {Dab-C-NH }}$ 
Figure 2

A
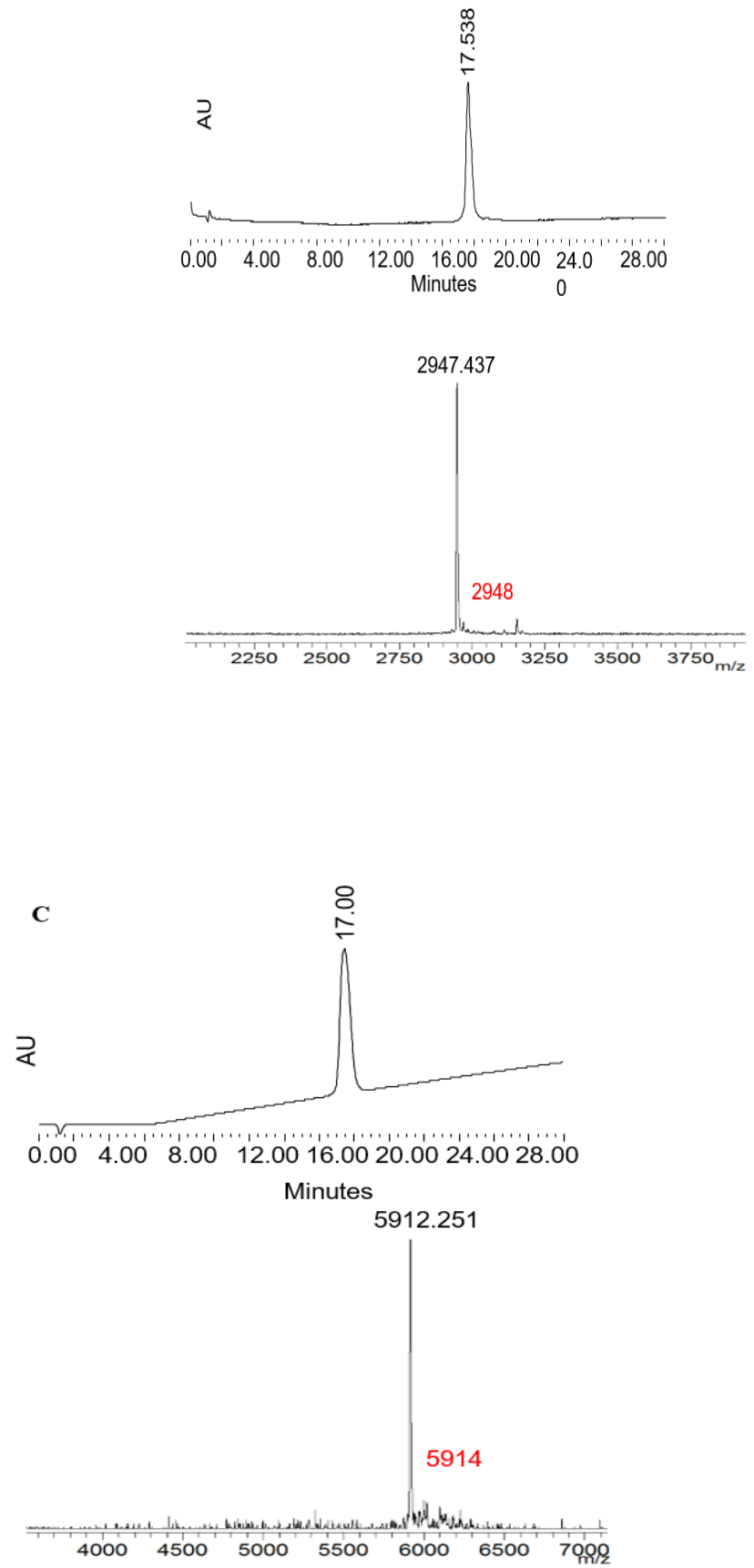
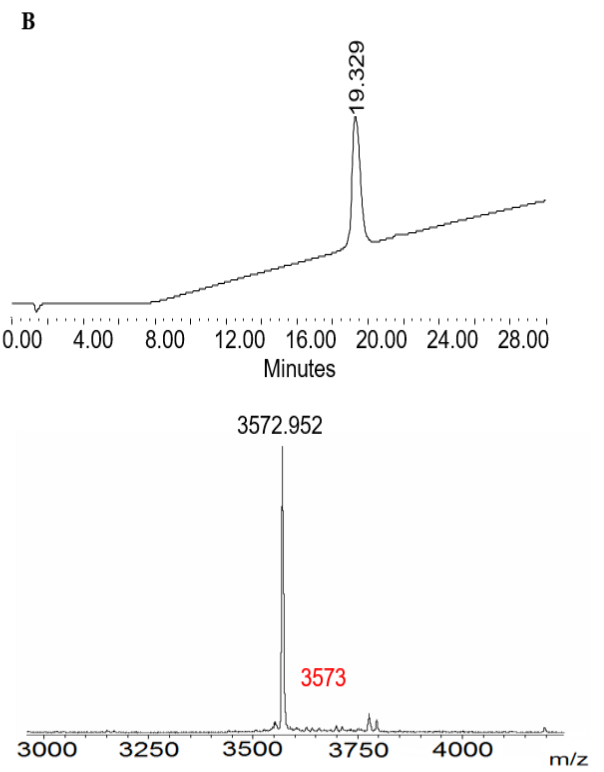

D

กำ
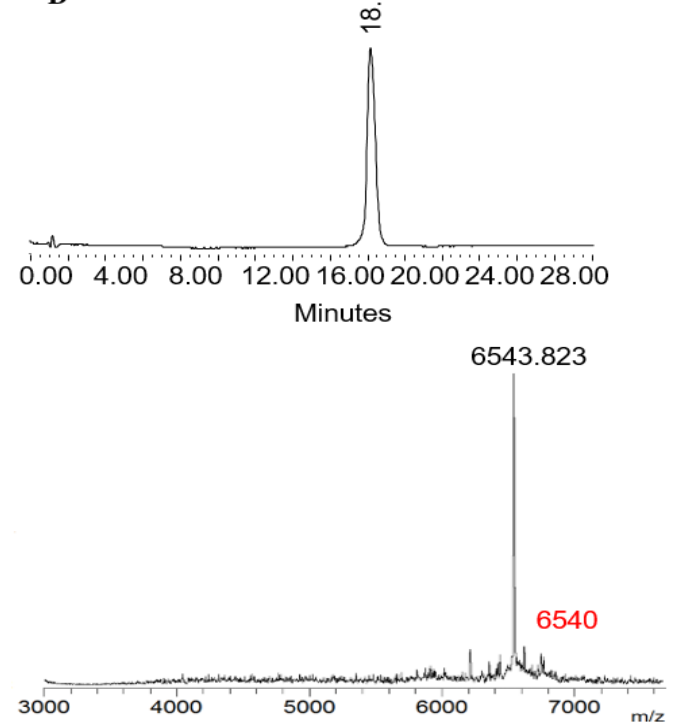
Figure 3

A
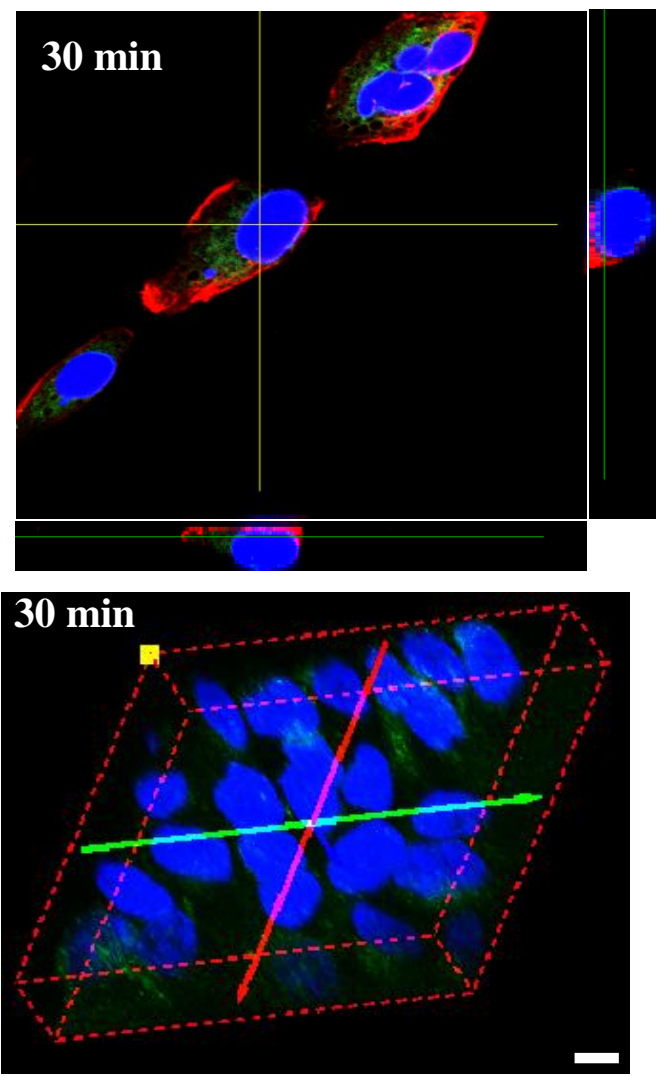

B
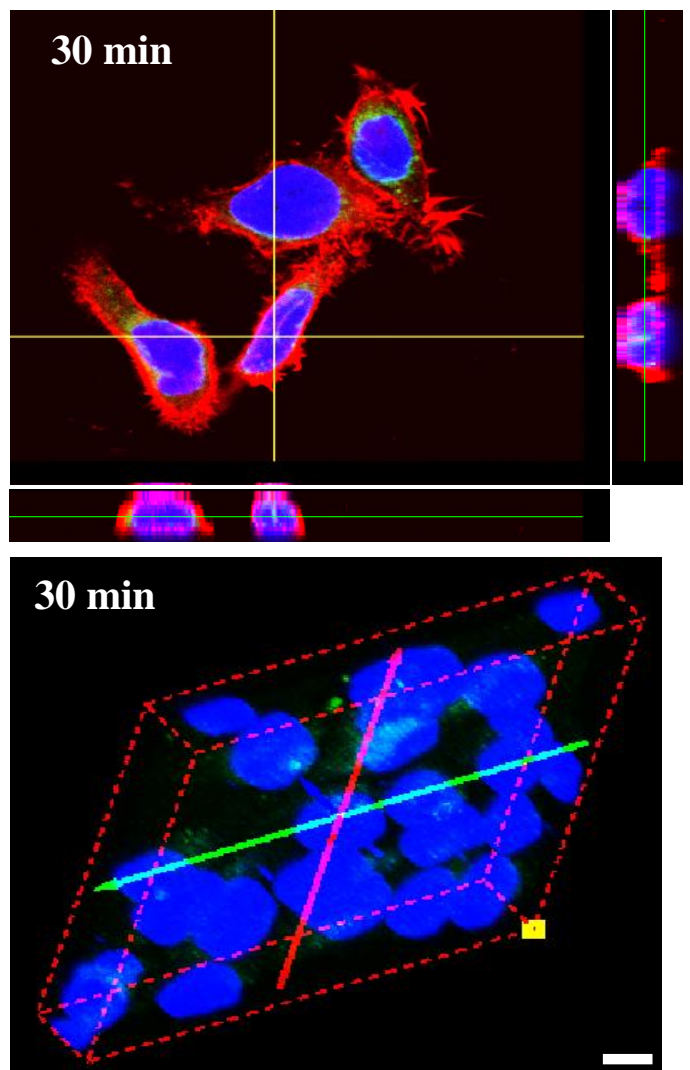
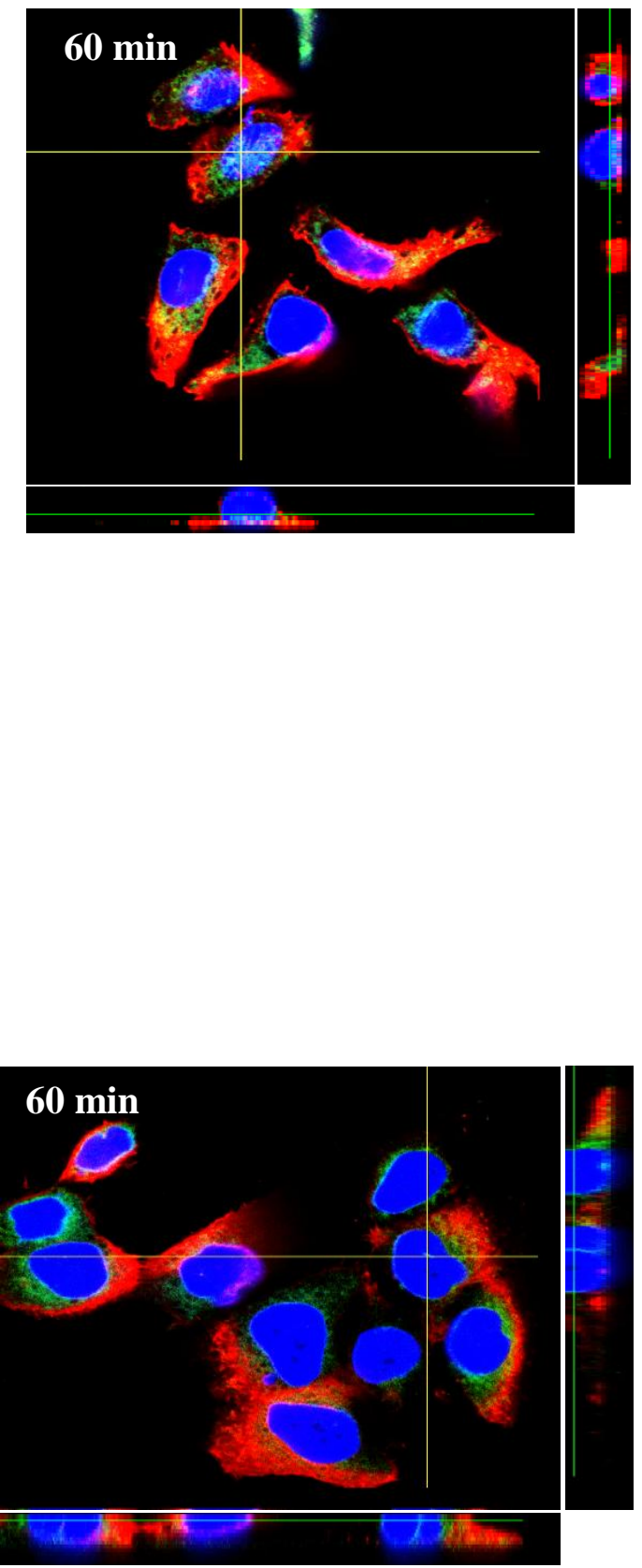
Figure 4

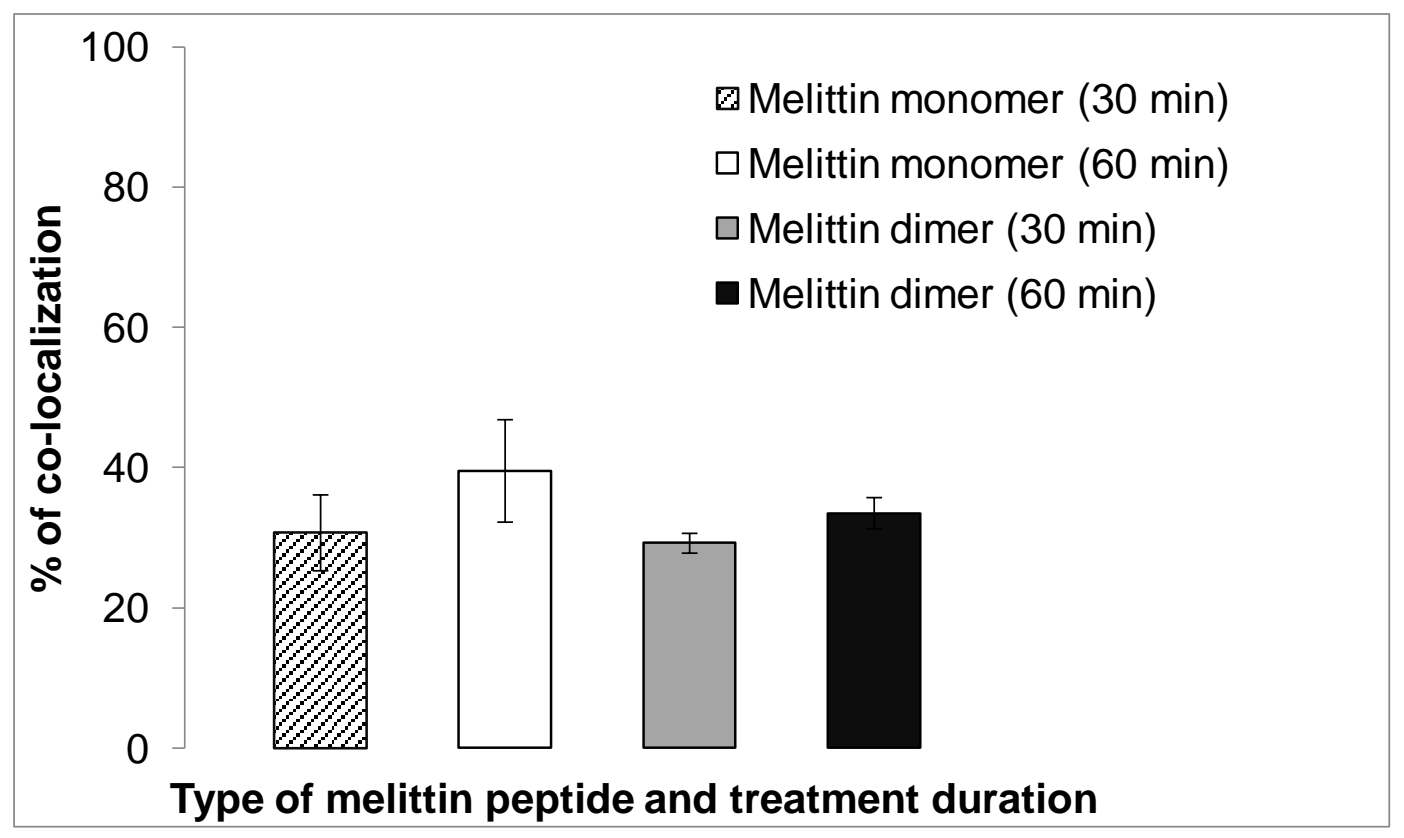


Figure 5

(A)

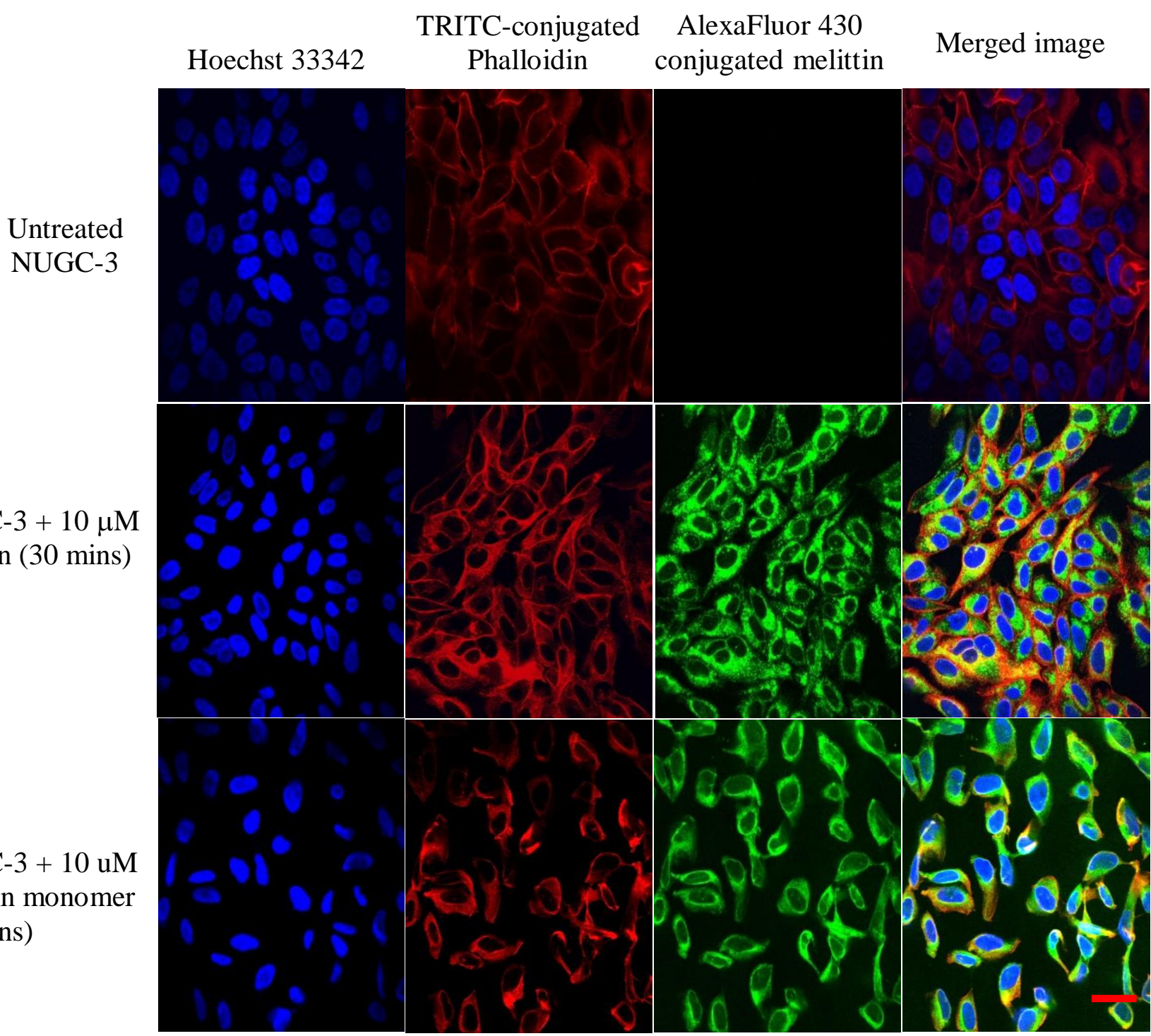


(B)

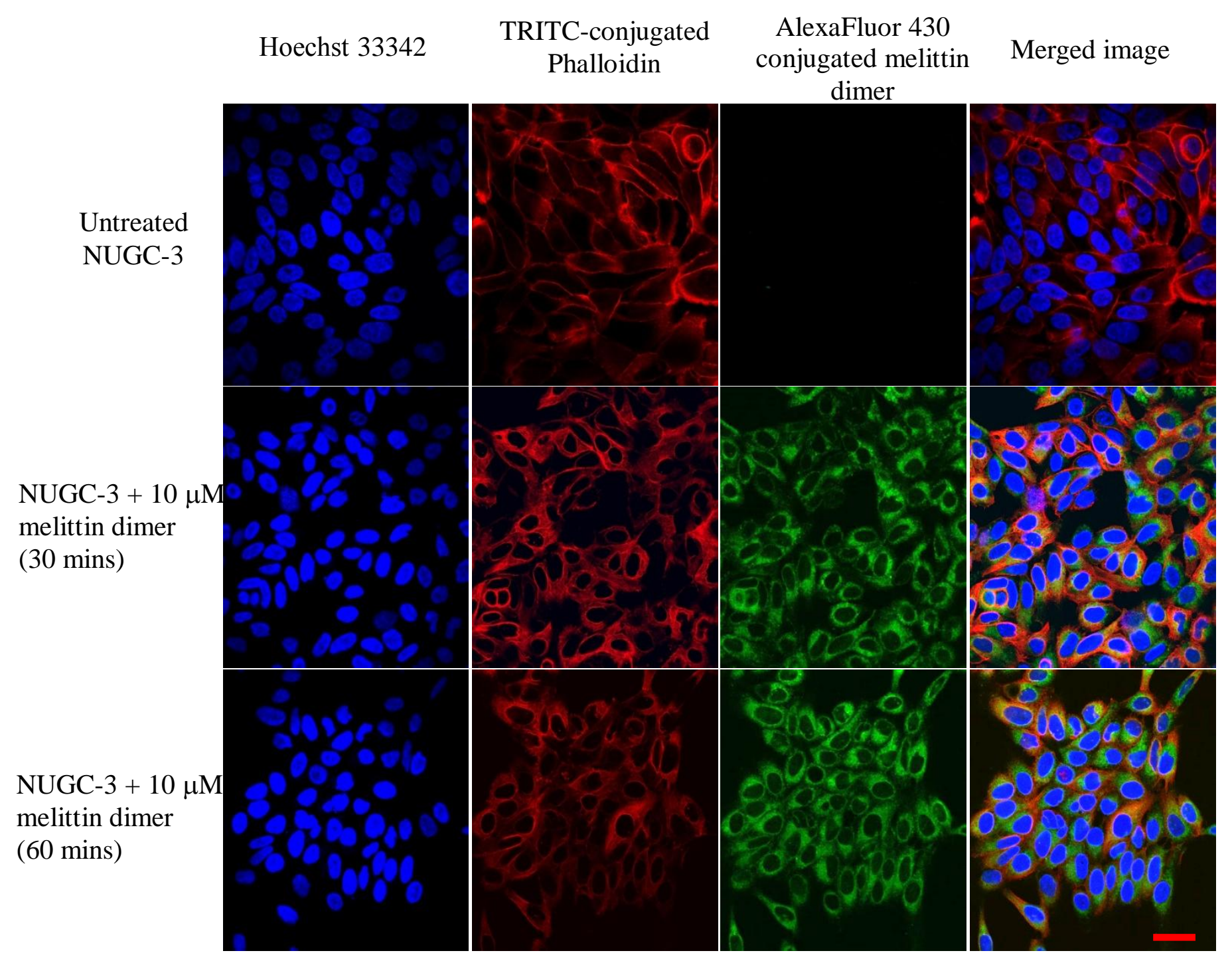


Figure 6

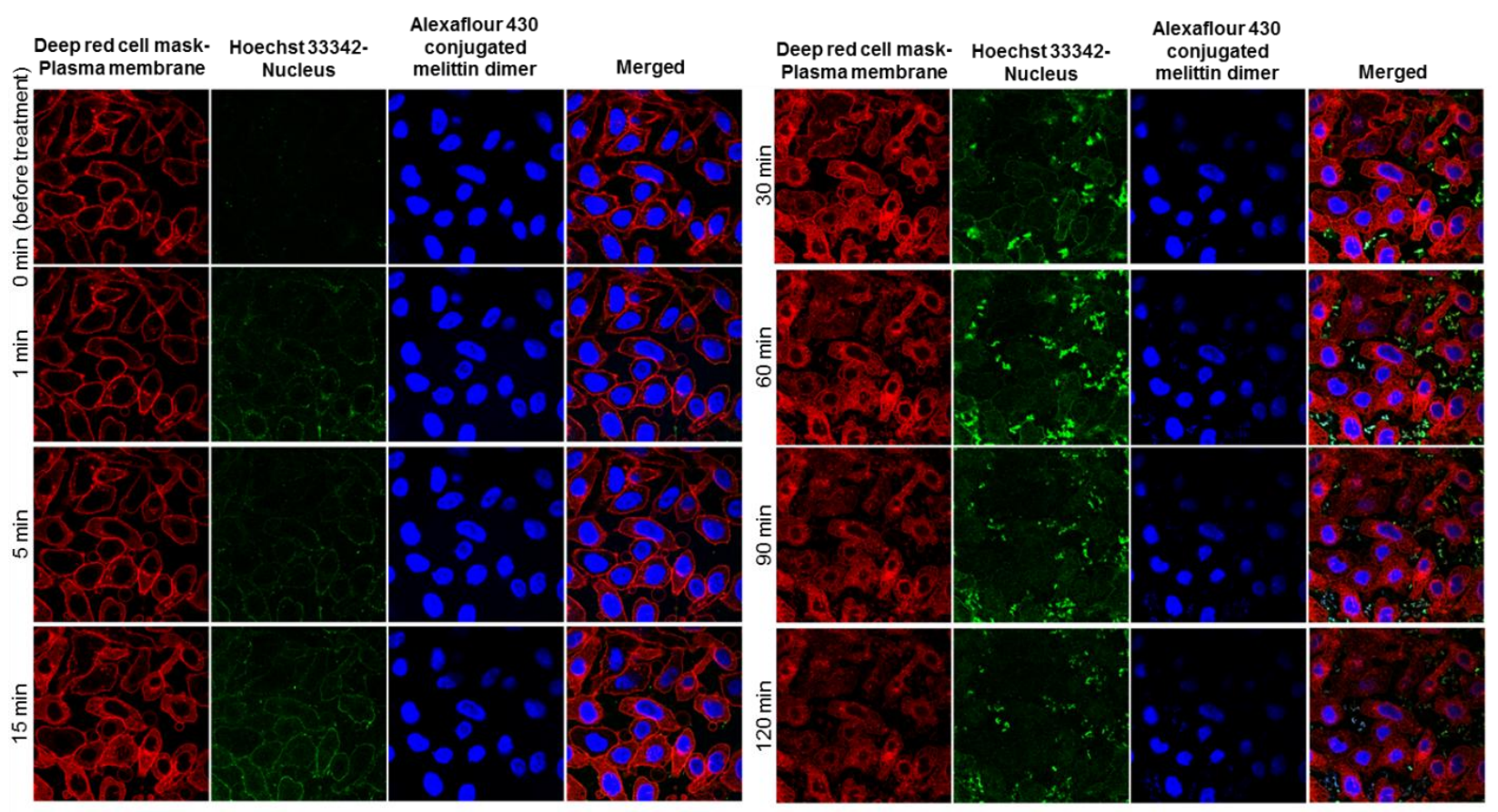


Figure 7
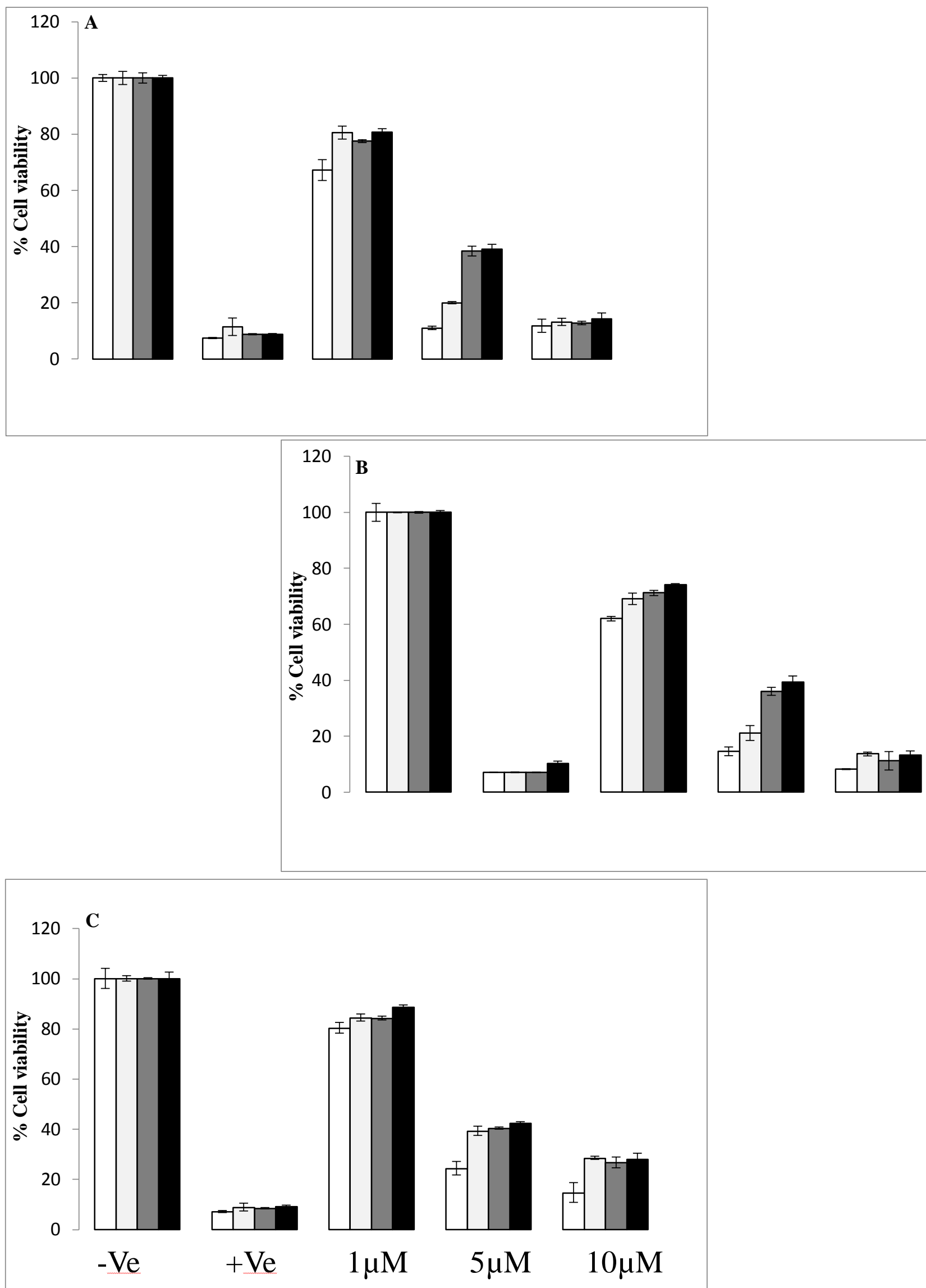
Figure 8

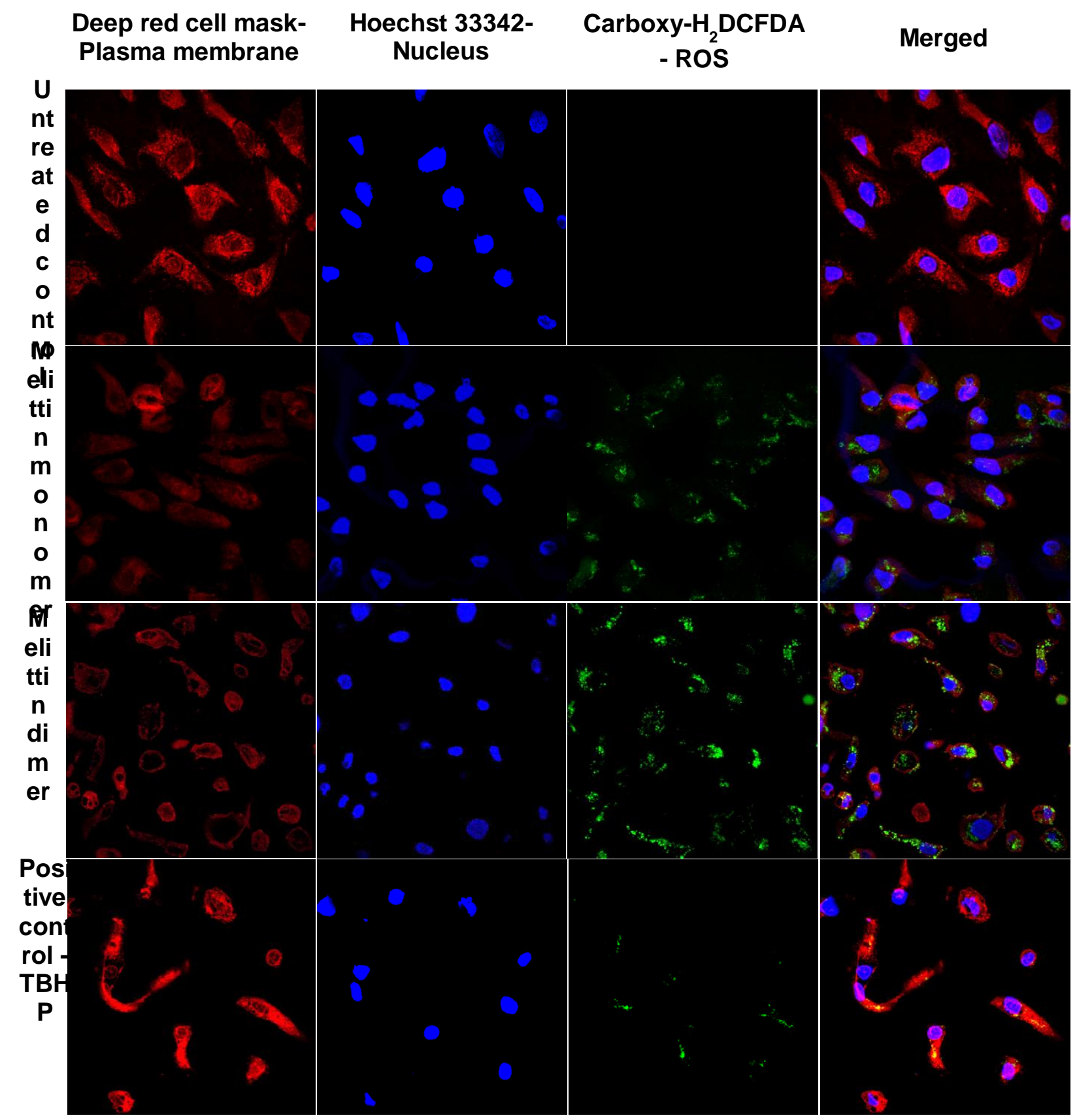


Figure 9
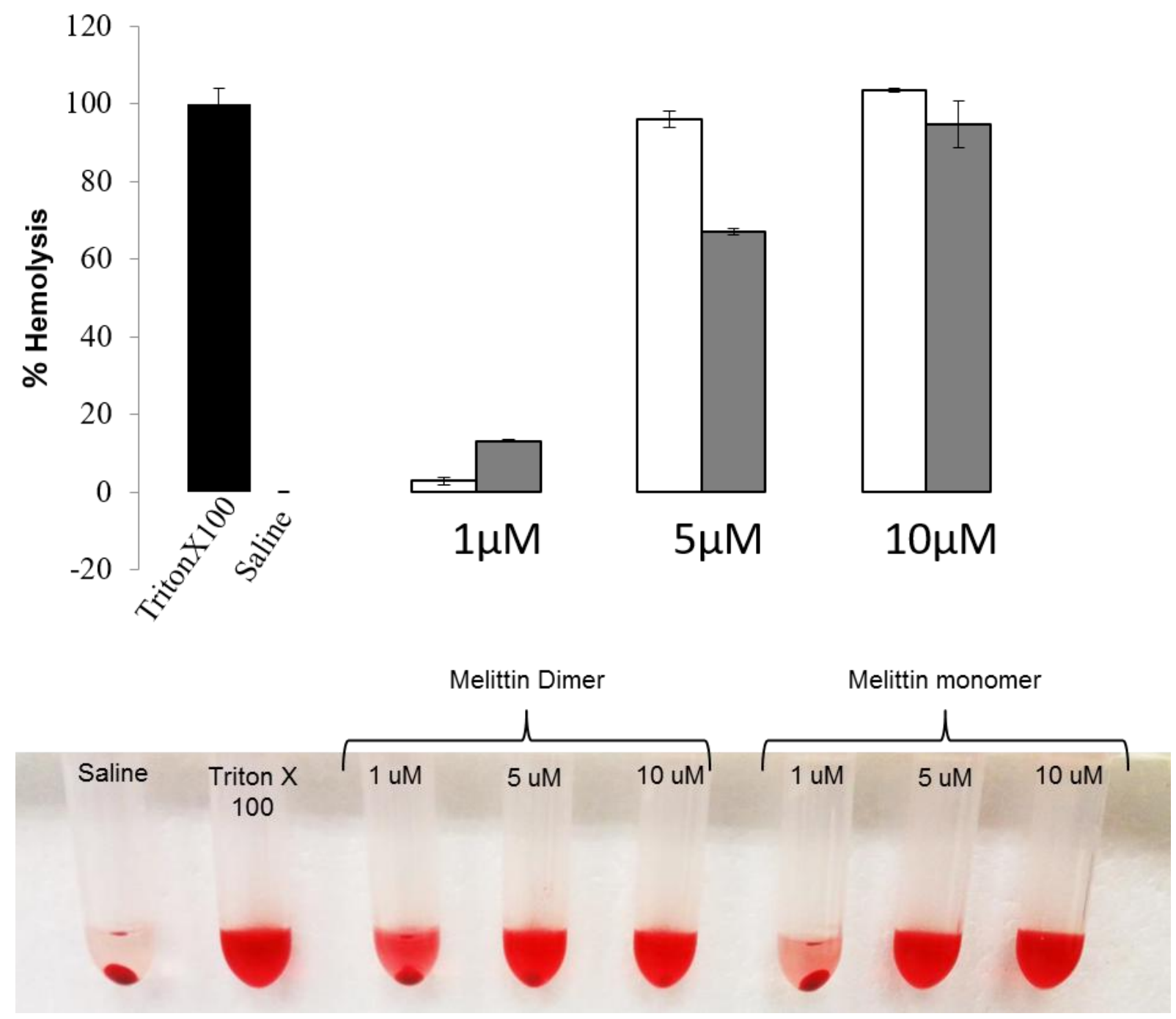